\title{
Effect of elastic columns on the mechanism of damage control for steel structures in Japan and the USA
}

\author{
Y. Kimura ${ }^{1} \&$ S. Hamazaki ${ }^{2}$ \\ ${ }^{I}$ Department of Structural Engineering, Nagasaki University, Japan \\ ${ }^{2}$ Graduate School of Nagasaki University, Japan
}

\begin{abstract}
There are some differences in steel structures from the point of view of seismic designs between the USA and Japan. Japanese typical frames are spatial moment resisting frames. USA frames are the perimeter frames, and the columns inside the frames are designed as gravity columns, which support only the weight of the buildings. Such columns may divide the shear force over the height of the frame and work as damage control systems. This study clarifies the drift deformation concentration for the standard steel moment resistant frames in the USA and Japan. The equations for the drift concentration are developed under the equilibrium conditions, and compared with the push over analyses results.

Keywords: USA and Japanese moment resisting frame, gravity column, drift concentration factor, ratio of column flexural stiffness.
\end{abstract}

\section{Introduction}

The typical structural system of steel buildings in the USA is perimeter frame, while the Japanese typical steel system is a spatial moment resisting frame. USA frames consist of seismic columns and gravity columns. While the gravity columns are designed not to carry the seismic forces and the role of the gravity columns is to support the weight of the building, they have some flexural stiffness. Such column flexural stiffness and strength are regarded as the redundancy of structures, and the effect of column properties on the soft story mechanism is supposed to be performed during an earthquake. While researches have been concerned about the possibility of drift concentration in frames (e.g. 
Paulay [1], Akiyama and Ohi 1981 [2], Krawinkler and Gupta 1998 [3]), no study except the authors has been performed to quantify the column stiffness and strength necessary to decrease drift concentration. Such a study has not been performed possibly because many typical frames tend to perform satisfactorily without explicitly studying drift concentration. However, it is important to clarify the relationship between continuous column properties and frame performance.

This paper compares the seismic performance for the typical USA and Japanese steel moment resisting frames, and clarifies the advantage in these frames. In particular, the story drift concentration is investigated and the effect of the column stiffness on the seismic behavior is related to the structural properties in the frames. The drift concentration factor is defined as the ratio of the maximum story drift angle to the roof drift angle, and the equations are developed using static equilibrium. Finally, using three-story and nine-story frames designed by the SAC project and Building Research Institute (BRI), a comparison of drift concentration between USA steel perimeter frames with gravity columns and Japanese spatial moment resisting frames was carried out though the pushover and dynamic analyses.

\section{Drift concentration factor for the USA and Japanese moment resisting frames}

\subsection{Assumptions of static equilibrium for USA and Japanese moment resisting frames subjected to lateral force}

In this section, the collapse mechanism for moment resisting frames subjected to seismic force is clarified. The following assumptions are used to develop the equation for the drift concentration factor (e.g. Kimura [4]).

1) There are two kinds of collapse mechanisms for moment resisting frames: i) only columns yield in a frame, and ii) beams yield and columns, except the base, remain elastic. In the latter case, beams and columns at the base yield almost at the same, so the base is assumed to be pinned after yielding.

2) The shear force, $V_{s i}$, in a frame is found from the $A_{i}$ lateral force distribution (e.g. $\mathrm{BCJ}$ [5]), and lateral force, $P_{i}$ is given in the following.

$$
P_{i}=V_{s i}-V_{s i+1} \quad(i=N)
$$

3) It is assumed that the relationship between inter-story shear force and story drift is elastic-perfectly plastic.

4) The ratio of the shear stiffness over height, $\beta$, is given in the following. The column stiffness ratio, $\alpha$, is defined as the ratio of the sum of the column flexural stiffness to the shear stiffness on the first story.

$$
\beta=\left\{\left(3 \sum_{i=1}^{N} K_{g i}\right) /\left(N K_{g 1}\right)\right\}-2(2), \quad \alpha=\left\{\left(\sum E I_{c} / h^{3}\right) / K_{g 1}\right.
$$

The shear stiffness of the frames is assumed to be the flexural pins at column mid-height as shown in Figure 2, and the shear stiffness on each story, $K_{g i}$, is (e.g. Muto et al. [6]) 
(a) Top story

$$
K_{g N}=\frac{6 E I_{b} I_{c}}{\left(l_{b} I_{c}+2 l_{c} I_{b}\right) l_{c}^{2}}
$$

(b) Middle stories

$$
K_{g i}=\frac{6 E I_{b} I_{c 1} I_{c 2}}{\left(2 l_{b} I_{c 1} I_{c 2}+l_{c} I_{b} I_{c 1}+l_{c} I_{b} I_{c 2}\right) l_{c}^{2}}, \quad i=2 \sim N-1
$$

(c) First story

$$
K_{g 1}=\frac{3 E I_{c}}{l_{c}^{3}}
$$

The drift concentration factor, $\gamma$, is defined as the ratio of maximum story drift angle, $\delta_{\max } / h$, to roof drift angle, $\Delta_{N} / H$.

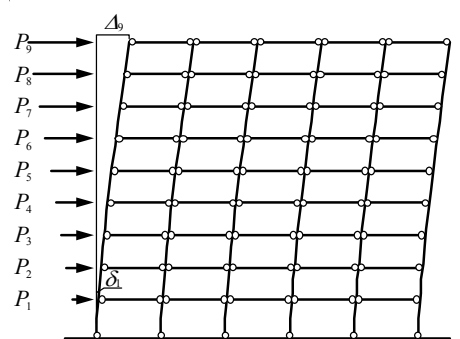

(a) Beam yielding model

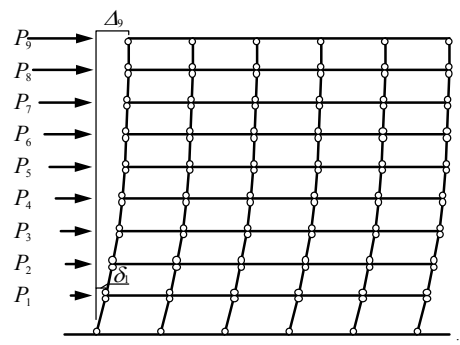

(b) Shear resisting model

Figure 1: Difference of collapse mechanism for moment resisting frames.

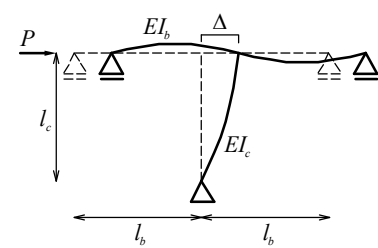

(a) Top story

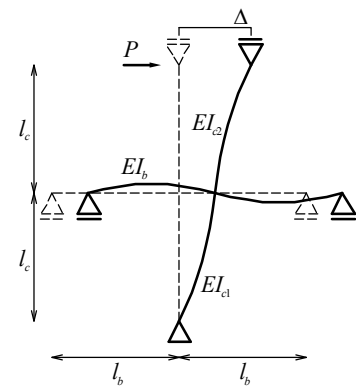

(b) Middle stories

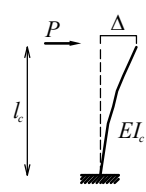

(c) First story

Figure 2: $\quad$ Partial frame models on each story.

\subsection{Development of drift concentration factor for USA and Japanese moment resisting frames}

A) One story yielding in a frame

The shear force in the total frame, $V_{s i}$, is the sum of the shear forces in the frame, $V_{f i}$, and that in the columns, $V_{c i}$, as follows. 


$$
V_{s i}=V_{f i}+V_{c i}, \quad i=1 \sim N, \quad V_{f 1}=V_{f l y}, \quad\left(V_{c 1}=-\sum_{i=2}^{N} V_{c i}\right)
$$

where $N$ is the story number of frames, and $i$ is the story counter. $V_{f l y}$ is the shear strength when any member yields in the frame. The shear force in the frame, $V_{s i}$, according to $A_{i}$ distribution is

$$
V_{s i}=\left\{C_{i} W_{i} /\left(C_{1} W_{1}\right)\right\} V_{s 1} \quad\left\{C_{i} W_{i} /\left(C_{1} W_{1}\right)\right\}=A_{i}, \quad i=1 \sim N
$$

The story shear force, $V_{f i}$, is given from the relationship between Eqs. (7) and (8).

$$
V_{f i}=-\left(A_{i}+1\right) V_{c i}-A_{i}\left(\sum_{l=2}^{N} V_{c l}-V_{c i}\right)+A_{i} V_{f 1 y}, i=2 \sim N
$$

The inter-story displacement on $i$ story of frames, $\delta_{f i}$, is given in the following.

$$
\delta_{f i}=V_{f i} / K_{g i}, \quad i=1 \sim N
$$

The inter-story displacement on $i$ story of column $\delta_{c i}$ is obtained using eqn. (10) and the differential of the shear forces $F_{c k}=V_{c i} V_{c, i+1}$ as shown in eqn. (11).

$$
\begin{gathered}
\delta_{c i}=\int_{0}^{H / N}\{(N-i) / N x A x\} d x+\sum_{j=1}^{N-1} \int_{j H / N}^{(j+1) H / N}\{(N-i) / N x-(x-i H / N)\} \\
\left\{\left(A-\sum_{k=1}^{j} F_{c k}\right) x+H / N \sum_{k=1}^{j} k F_{c k}\right\} d x
\end{gathered}
$$

where $(x-i H / N)=0$ when $j=i-1(i=2 \sim N)$.

$\delta_{c i}$ is also obtained using the story yield displacement at top of frame, $\Delta_{N y}$, as shown in eqn. (12).

$$
\begin{aligned}
& \delta_{c i}=\sum_{i=1}^{i} \delta_{f i}-i / N \Delta_{N y} \quad\left(\sum_{i=1}^{N} \delta_{f i}=\Delta_{N y}\right), \quad i=1 \sim N-1 \\
& \delta_{c i}=\left\{(N-i) \sum_{i=1}^{i} \delta_{f i}-i \sum_{i=i+1}^{N} \delta_{f i}\right\} / N
\end{aligned}
$$

Substituting Eqs. (9) and (10) for eqn. (12), $\delta_{c i}$ is given in the following.

$$
\begin{aligned}
\delta_{c i}=\{( & (N-i) \sum_{i=1}^{i}\left(-\left(A_{i}+1\right) V_{c i}-A_{i}\left(\sum_{l=2}^{N} V_{c l}-V_{c i}\right)+A_{i} V_{f 1 y}\right) / K_{g i} \\
& \left.-i \sum_{i=i+1}^{N}\left(-\left(A_{i}+1\right) V_{c i}-A_{i}\left(\sum_{l=2}^{N} V_{c l}-V_{c i}\right)+A_{i} V_{f 1 y}\right) / K_{g i}\right\} / N
\end{aligned}
$$

As eqn. (11) is equal to eqn. (13), the shear force in the column, $V_{c i}$, is developed with $V_{f l y}$ and the drift on $i$ story, $\delta_{f i}$ is obtained from eqn. (9). The story drift concentration factor, $\gamma$, when any member yields in the frame, is the ratio of the maximum story drift angle to the yielding roof drift angle in the following.

$$
\gamma=\left(\delta_{f i} / h\right) /\left(\Delta_{N y} / H\right)
$$

B) $n$ stories yielding in a frame

In this section, the drift concentration factor, $\gamma$, at $n$ stories yielding is developed.

$$
\Delta V_{s i, n}=\Delta V_{f i, n}+\Delta V_{c i, n}, \Delta V_{c 1}=-\sum_{i=2}^{N} \Delta V_{c i}
$$


where $\Delta$ is the incremental quantity, $n$ is the number of stories yielding and $i$ is the $1 \sim N$. The additional shear force, $\Delta V_{f i, n}$, below $n-1$ stories will be equal to 0 when $n$ stories yield in a frame. The additional shear force in the system based on $A_{i}$ distribution, $\Delta V_{s i, n}$, is given in eqn. (16).

$$
\Delta V_{s i, n}=\left\{C_{i} W_{i} /\left(C_{1} W_{1}\right)\right\} \Delta V_{s 1, n}, \quad\left\{C_{i} W_{i} /\left(C_{1} W_{1}\right)\right\}=A_{i}, \quad i=1 \sim N
$$

Also, the additional shear force in the system is obtained from eqn. (16) in the following.

$$
\Delta V_{f i, n}=-\left\{A_{i} /\left(\sum_{t=2}^{n} A_{t-1}\right)+1\right\} \Delta V_{c i, n}-A_{i} /\left(\sum_{t=2}^{n} A_{t-1}\right)\left(\sum_{l=n}^{N} \Delta V_{c l, n}-\Delta V_{c i, n}\right), \quad i=2 \sim N
$$

The additional story displacement, $\Delta \delta_{f i, n}$, and the relative flexural displacement of the column, $\delta_{c i, n}$, are obtained from static equilibrium in the following.

$$
\begin{gathered}
\Delta \delta_{f i, n}=\Delta V_{f i, n} / K_{g i}, \quad i=1 \sim N \\
\Delta \delta_{c i, n}=\int_{0}^{H / N}\{(N-i) / N x A x\} d x+\sum_{j=1}^{N-1} \int_{j H / N}^{(j+1) H / N}\{(N-i) / N x-(x-i H / N)\} \\
\left\{\left(A-\sum_{k=1}^{j} \Delta F_{c k, n}\right) x+H / N \sum_{k=1}^{j} k \Delta F_{c k, n}\right) d x
\end{gathered}
$$

where $\Delta F_{c k, n}=\Delta V_{c i, n}-\Delta V_{c i+1, n}$ and $(x-i H / N)=0$ when $j=i-1(i=2 \sim N)$.

$$
\begin{gathered}
\Delta \delta_{c i, n}=\sum_{m=1}^{i} \Delta \delta_{f m, n}-(i / N)\left(\mu_{n}-\mu_{n-1}\right) \Delta_{N y}, \quad i=1 \sim N-1 \\
\Delta \delta_{f i, n}=-\Delta \delta_{c i-1, n}+\Delta \delta_{c i, n}+(1 / N)\left(\mu_{n}-\mu_{n-1}\right) \Delta_{N y}, \quad i=1 \sim N, \delta_{c 0}=0, \delta_{c N}=0
\end{gathered}
$$

Substituting $\Delta \delta_{c i, n}$ of eqn. (19) for eqn. (21), the additional inter-story displacement by column flexural deformation, $\Delta \delta_{f i(f l e x u r a l), n}$, is shown in the following:

$$
\begin{array}{rl}
\Delta \delta_{f i(\text { flexural }), n}=-\Delta \delta_{c i-1, n}+\Delta \delta_{c i, n}+ & (1 / N)\left(\mu_{n}-\mu_{n-1}\right) \Delta_{N y}, \\
i & i \sim N, \quad \delta_{c 0}=0, \quad \delta_{c N}=0
\end{array}
$$

where $\mu_{n}$ is the roof ductility at $n$ stories yielding.

Substituting eqn. (17) to eqn. (18), the additional inter-story displacement of the frame, $\Delta \delta_{f(\text { shear }), n}$, is obtained in the following:

$$
\Delta \delta_{f i(\text { shear }), n}=\left[-\left\{A_{i} /\left(\sum_{t=2}^{n} A_{t-1}\right)+1\right\} \Delta V_{c i, n}-A_{i} /\left(\sum_{t=2}^{n} A_{t-1}\right)\left(\sum_{l=n}^{N} \Delta V_{c l, n}-\Delta V_{c i, n}\right)\right] / K_{g i},
$$

where $i=2 \sim N$.

As eqn. (22) is equal to eqn. (23), the shear force in the column, $\Delta V_{c i, n}$ is expressed with $\left(\mu_{n}-\mu_{n-1}\right) \Delta_{N y} / N$ and the flexural column displacement on $i$ story, $\Delta \delta_{c i, n}$, is obtained from eqn. (20). Finally, the additional displacement on $i$ story, $\Delta \delta_{f i, n}$, is obtained.

In the range from first story yielding to $n$ stories yielding, the story drift concentration factor, $\gamma$, is the ratio of the maximum total story drift angle to the yielding roof drift angle in the following (e.g. MacRae et al. [7]): 


$$
\gamma=\left[M A X\left\{\left(\delta_{f i, 1}+\sum_{n=2}^{n} \Delta \delta_{f i, n}\right)\right\} / h\right] /\left(\Delta_{N y, n} / H\right)
$$

C) After full mechanism

In this section, the drift concentration factor after full mechanism is developed.

As the total roof displacement is obtained from the roof ductility, the additional roof displacement, $\Delta \delta_{f i, N}$, is given in eqn. (25):

$$
{ }_{\Delta} \delta_{f i, N}=1 / N\left(\mu-\mu_{N}\right) \Delta_{N y}
$$

where $\mu_{N}$ is the roof ductility at mechanism formation. The drift concentration factor, $\gamma$, after full mechanism is obtained using the sum of the maximum story displacements $\delta_{f i, 1}$ and $\Delta \delta_{f i, n}$ and the roof displacement after mechanism formation, $\Delta_{N y, N}$ in the following:

$$
\gamma=\left[M A X\left\{\left(\delta_{f i, 1}+\sum_{n=2}^{n} \Delta \delta_{f i, n}+\Delta \delta_{f i, N}\right)\right\} / h\right] /\left(\Delta_{N y, N} / H\right)
$$

The increase of column shear force after full mechanism is assumed to be 0 .

\section{Evaluation of seismic capacity for USA and Japanese moment resisting frames subjected to static lateral forces}

\subsection{Difference of structural property between USA and Japanese frames}

Figure 3 shows the models for nine-story frames as shown in Figure 3 (e.g. Hasegawa et al. [8]). The solid lines show rigid frame, and the dotted lines show pinned frame. It is shown that the BRI frames are the spatial moment resisting frames and the SAC frames are the perimeter frames. Columns inside the SAC frames are designed as gravity columns. In the SAC frames, masses for the analysis frames have been computed on the basis of are equal to $1 / 2$ floor, and in the BRI frames, the masses have been computed with $1 / 6$ and $1 / 5$ of the total mass attributed to each analyzed frame in the three and nine-story buildings, respectively.

Table 1: $\quad$ Structural property of frames.

\begin{tabular}{|l|c|c|}
\hline \multicolumn{1}{|c|}{ Frame Type } & $\alpha$ & $\beta$ \\
\hline BRI3-A & 0.92 & 0.61 \\
\hline BRI3-B & 0.78 & 0.61 \\
\hline SAC3-LA-2D & 0.70 & 1.00 \\
\hline SAC3-LA-3D & 3.10 & 1.00 \\
\hline BRI9-A & 5.40 & 0.65 \\
\hline BRI9-B & 5.62 & 0.21 \\
\hline SAC9-LA-2D & 4.40 & 0.41 \\
\hline SAC9-LA-3D & 5.24 & 0.41 \\
\hline
\end{tabular}

Tables 1 and 2 show the member size and structural properties of nine-story frames, respectively. Box section for the BRI frames or $\mathrm{H}$ section for the SAC frames is used for columns. It means that all columns in SAC frames bend about 
the strong axes and those in BRI frames are used to resist bi-axial bending. There are two kinds of analytical models for SAC9, which are plane models (2D models) and space models (3D models) because 2D and 3D frames are supposed to perform different seismic behavior due to the flexural stiffness of gravity columns.

Table 2: $\quad$ Member section in nine-story frames.

\begin{tabular}{|c|c|c|c|c|c|c|c|c|}
\hline \multirow{3}{*}{$\begin{array}{l}\text { Story/ } \\
\text { Floor }\end{array}$} & \multicolumn{2}{|c|}{ BRI9-A } & \multicolumn{3}{|c|}{ BRI9-B } & \multicolumn{3}{|c|}{ SAC9 } \\
\hline & $\begin{array}{l}\text { Column } \\
\text { (BCP325) }\end{array}$ & \multirow[t]{2}{*}{$\begin{array}{c}\text { Girder } \\
\text { (SN400B) }\end{array}$} & $\begin{array}{c}\text { Column } \\
\text { (BCP325) }\end{array}$ & \multicolumn{2}{|c|}{$\begin{array}{c}\text { Girder } \\
\text { (SN490B) } \\
\end{array}$} & \multicolumn{2}{|c|}{$\begin{array}{l}\text { Column } \\
(50 \text { ski) }\end{array}$} & \multirow[t]{2}{*}{$\begin{array}{l}\text { Girder } \\
(36 \mathrm{ksi})\end{array}$} \\
\hline & \begin{tabular}{l|l} 
Ext. & Int.
\end{tabular} & & \begin{tabular}{l|l} 
Ext. & Int.
\end{tabular} & $\begin{array}{ll}\text { Ext. } \\
\end{array}$ & Int. & Ext. & Int. & \\
\hline $9 / 10$ & \multirow{3}{*}{$\square-450 \times 19$} & \multirow{3}{*}{$\begin{array}{c}\mathrm{H}-450 \times 250 \times \\
9 \times 16\end{array}$} & \multirow[t]{2}{*}{$\square-450 \times 16$} & \multirow{2}{*}{\multicolumn{2}{|c|}{ H- $500 \times 250 \times 9 \times 16$}} & $\begin{array}{c}\text { W14×233 } \\
(\mathrm{H}-409 \times 404\end{array}$ & $\begin{array}{l}\text { W14×257 } \\
(\mathrm{H}-419 \times 407\end{array}$ & $\begin{array}{c}\text { W24×68 } \\
(\mathrm{H}-602 \times 228 \\
\times 11 \times 15)\end{array}$ \\
\hline $8 / 9$ & & & & & & $\times 28 \times 44)$ & $\times 31 \times 49)$ & $\begin{array}{c}\text { W27×84 } \\
(\mathrm{H}-678 \times 253 \\
\times 12 \times 16)\end{array}$ \\
\hline $7 / 8$ & & & \multirow{3}{*}{$\square-450 \times 19$} & $\begin{array}{c}\mathrm{H}-500 \times 250 \\
\times 9 \times 19\end{array}$ & $\begin{array}{c}\mathrm{H}-500 \times 250 \\
\times 9 \times 16\end{array}$ & $\begin{array}{c}\mathrm{W} 14 \times 257 \\
(\mathrm{H}-419 \times 407\end{array}$ & $\begin{array}{c}\mathrm{W} 14 \times 283 \\
(\mathrm{H}-427 \times 410\end{array}$ & $\begin{array}{c}\text { W30×99 } \\
(\mathrm{H}-753 \times 266 \\
\times 13 \times 17) \\
\end{array}$ \\
\hline $6 / 7$ & \multirow{3}{*}{$\square-500 \times 19$} & \multirow{3}{*}{$\begin{array}{c}\mathrm{H}-500 \times 250 \times \\
12 \times 22\end{array}$} & & \multirow{2}{*}{$\begin{array}{c}\mathrm{H}-500 \times 200 \\
\times 9 \times 22\end{array}$} & \multirow{2}{*}{$\begin{array}{c}\mathrm{H}-500 \times 250 \\
\times 9 \times 19\end{array}$} & & & \multirow{4}{*}{$\begin{array}{c}\text { W36×135 } \\
(\mathrm{H}-903 \times 303 \\
\times 15 \times 20)\end{array}$} \\
\hline $5 / 6$ & & & & & & $\begin{array}{c}\mathrm{W} 14 \times 283 \\
\mathrm{H}-427 \times 410\end{array}$ & $\begin{array}{c}\mathrm{W} 14 \times 370 \\
\mathrm{H}-456 \times 418\end{array}$ & \\
\hline $4 / 5$ & & & \multirow{3}{*}{$\square-450 \times 22$} & \multirow{3}{*}{$\begin{array}{c}\mathrm{H}-600 \times 250 \\
\times 12 \times 22\end{array}$} & \multirow{3}{*}{$\begin{array}{c}\mathrm{H}-600 \times 250 \\
\times 12 \times 19\end{array}$} & $\times 33 \times 53)$ & $\times 42 \times 68)$ & \\
\hline $3 / 4$ & \multirow{3}{*}{$\square-500 \times 22$} & \multirow{2}{*}{$\mid \begin{array}{c}\mathrm{H}-550 \times 250 \times \\
12 \times 22\end{array}$} & & & & \multirow{3}{*}{$\begin{array}{c}\text { W14×370 } \\
(\mathrm{H}-456 \times 418 \\
\times 42 \times 68)\end{array}$} & $\begin{array}{c}\text { W14×455 } \\
(\mathrm{H}-484 \times 427\end{array}$ & \\
\hline $2 / 3$ & & & & & & & $\times 51 \times 82)$ & \multirow{2}{*}{$\begin{array}{c}\text { W36×160 } \\
(\mathrm{H}-914 \times 305 \\
\times 17 \times 26)\end{array}$} \\
\hline $1 / 2$ & & $\begin{array}{c}\mathrm{H}-650 \times 250 \times \\
12 \times 25\end{array}$ & $\square-550 \times 25$ & $\begin{array}{c}\mathrm{BH}-700 \times 250 \\
\times 14 \times 22\end{array}$ & $\begin{array}{c}\mathrm{BH}-700 \times 25 \mathrm{C} \\
\times 14 \times 19\end{array}$ & & \begin{tabular}{|c|}
$\mathrm{W} 14 \times 500$ \\
$(\mathrm{H}-499 \times 432$ \\
$\times 56 \times 89)$ \\
\end{tabular} & \\
\hline
\end{tabular}

\subsection{Plan and evaluation of nine-story frames}

\subsection{Story drift and yielding mechanism for USA and Japanese moment resisting frames}

Figure 4(a) shows the relationship between lateral load and roof displacement angle. Where, $Q_{l}$ is the base shear force, $W_{l}$ is the total weight of the frame and $R_{t}$ is the vibration property coefficient. The Strength of nine-story frames is almost same except that of SAC9-2D.

Figure 4(b) compares the story drift concentration factor, $\gamma$. The value of $\gamma$ for SAC9-3D is smaller than that for SAC9-2D after roof displacement of 0.015 ( $\mathrm{rad}$ ) which means the first yielding step in the frames. It is shown that the columns inside carry the shear force after the frame yielding.

Figure 5 compares the drift concentration factor for USA and Japanese frames. There are 2 kinds of frames and one of them is named as Type A which is the shear resist frame and only columns yield in the frame. The other is named as Type-B, which yields at beams and column at the first story. For USA and Japanese frames, $\gamma$ increases with increasing of roof ductility, $\mu$, where $\mu$ is the roof ductility from the roof displacement divided by the first yield displacement in the frame. Type A concentrates the drift at $1^{\text {st }}$ story even though no drift 
concentration occurs for Type B. It may be shown that the column to remain elastic except the base is effective in reducing story drift concentration. The value of $\gamma$ for SAC-3D is smaller than that for SAC-2D, because column flexural

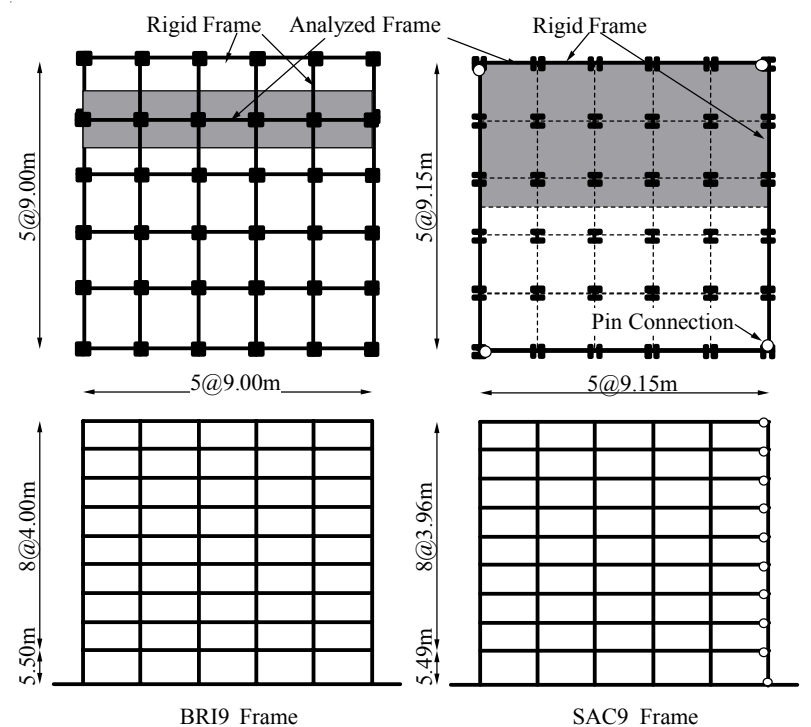

Figure 3: $\quad$ Plan and evaluation of nine-story frames.

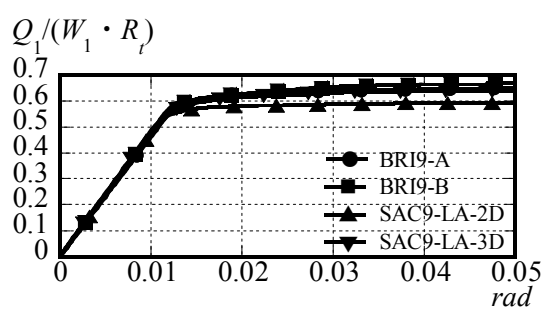

(a) Base shear strength

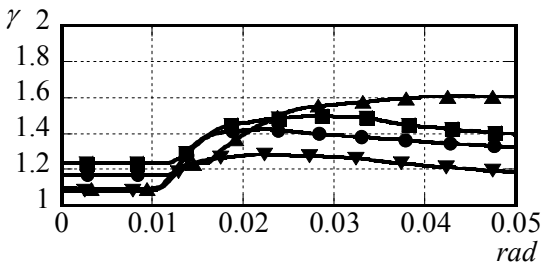

(b) Story drift concentration factor

Figure 4: Results of pushover analysis for nine-story frames.

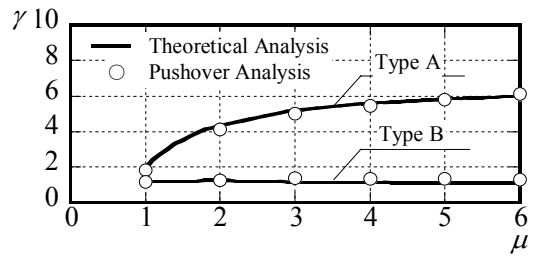

(a) BRI9-A

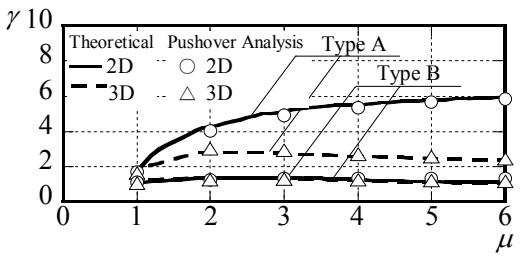

(b) SAC9

Figure 5: Relationship between drift concentration factor and collapse mechanism. 
stiffness for SAC-3D is lager than that for SAC-2D. As would be expected, the results from analyses and the equations are almost same. $\gamma$ may be approximated using Eqs. (14), (24) and (26).

\section{Seismic behavior for USA and Japanese moment resisting frames}

\subsection{Summary of dynamic analysis for USA and Japanese moment resisting frames}

The models for dynamic analysis [9] are same as those for pushover analysis. Damping was applied as $2 \%$ of critical in the first and $N_{\text {th }}$ mode using a Rayleigh damping model where $N$ is the number of stories. Newmark's constant average acceleration integration method was used in the inelastic dynamic time history analysis. These frames were analyzed with 12 records, EL Centro $1940 \mathrm{NS} / \mathrm{EW}$, Taft 1952 NS/EW, Tohoku 1978 NS/EW, Hachinohe 1968 NS/EW, Kobe 1995 $N S / E W, B C J-L 1 / L 2$ with a maximum velocity of 50 kine and 75 kine.

\subsection{Estimation of drift concentration factor for USA and Japanese moment resisting frames}

Figure 6 shows the dynamic drift concentration factor, $\gamma_{d}$ against the static value, $\gamma$ for three- and nine-story frames. Where, $\gamma_{d}$ was computed from the peak story drift and the peak roof drift even though these can occur at different times. For most analyses, the dynamic value is greater than static value as a result of the cyclic loading effects and the changing lateral force distribution.

Figure 7 shows the effect of gravity column flexural stiffness for the SAC frames on the dynamic drift concentration. $\gamma_{d-3 \mathrm{D}}$ is the drift concentration factor for 3D-frames and $\gamma_{d-2 \mathrm{D}}$ is that for 2D-frames as shown in Figure 3(b). The value of $\gamma_{d-3 \mathrm{D}}$ is smaller than that of $\gamma_{d-2 \mathrm{D}}$ for both of three- and nine-story frames. It was shown that the gravity columns resist the tendency for concentration of deformation in one story even though the gravity columns are not designed as seismic elements.

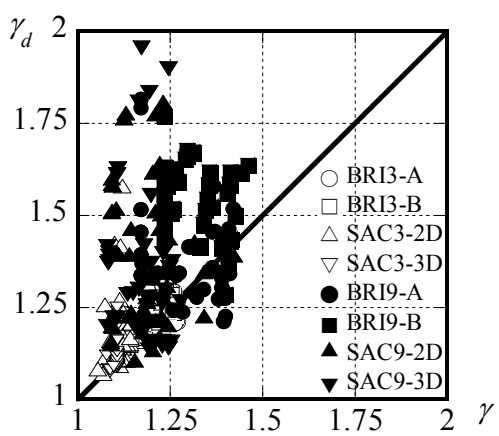

Figure 6: Comparison between static and dynamic drift concentration factors. 


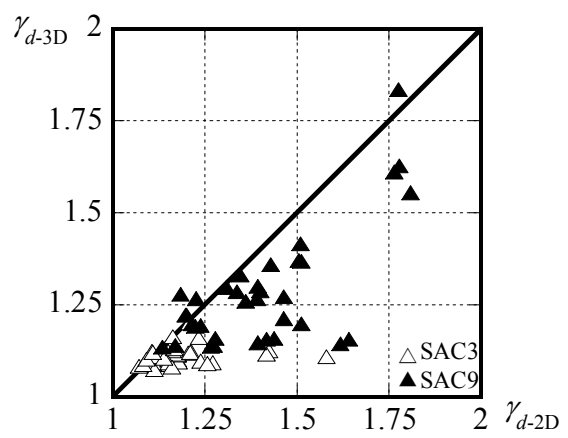

Figure 7: Effect of gravity columns on drift concentration factor for SAC frames.

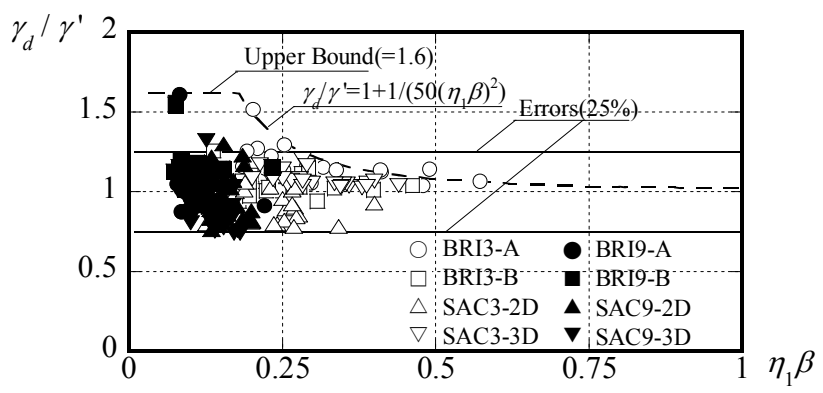

Figure 8: Estimation of drift concentration factor with dynamic shaking effect.

Figure 8 shows the drift concentration factor with the dynamic effects. ${ }_{1} \beta$ is participation factor and $\eta=a /\left(g^{*} R_{t}\right)$ as the modification coefficient, where $a$ is the response spectra of the acceleration for the natural period of frames at the maximum plastic deformation, $g$ is the acceleration of gravity and $R_{t}$ is the vibration property coefficient. $\gamma^{\prime}=1.5 N /(N+2.5)$ as the modification of the drift concentration factor. Where, $N$ is the story number of the frames. The results of the drift concentration factor with the dynamic effects are estimated by the following equation as the upper bound.

$$
\gamma_{d} / \gamma^{\prime}=1+\frac{1}{50\left(\eta_{1} \beta\right)^{2}} \quad\left(\gamma_{d} / \gamma^{\prime} \leq 1.6\right)
$$

The difference between the static $\gamma$ and dynamic $\gamma_{\mathrm{d}}$ converges in the range of less than $25 \%$ using the modification coefficient.

\section{Conclusion}

1) A procedure to estimate the drift concentration factor in moment resisting frames is developed to divide the seismic elements into the shear-resisting element and the flexural resisting element. 
2) The drift concentration factor is reduced by the gravity columns over the height of the structures in USA during the ground motions, while they carry no lateral shear force for the frames subject to pushover analysis.

3) The dynamic drift concentration factor is estimated by the equations based on the static drift concentration factor, and the difference converges less than $25 \%$.

\section{Acknowledgements}

The author acknowledges support from the National Research Institute for Earth Science and Disaster Prevention (NIED) and Japan Ministry of Education, Culture, Sport, Science, and Technology (MEXT), Grant-in Aid for Scientific Research (C) 19560574.

\section{References}

[1] Paulay T. (1978). "A Consideration of P- $\Delta$ Effects in Ductile Reinforced Concrete Frames", Bulletin of the New Zealand National Society for Earthquake Engineering, 111(3), 151-160.

[2] Akiyama, H. and Ohi, K. (1981). "Damage concentration of shear-type multi-story buildings with composite-type of restoring force characteristics" Transactions of the Architectural Institute of Japan, 303, May, pages 31-39 (in Japanese)

[3] Krawinkler, H. and Gupta, A. (1998). "Story Drift Demands for Steel Moment-Resisting Frame Structures", $6^{\text {th }}$ US National Conference on Earthquake Engineering, Seattle, WA, May 31-June 4.

[4] Yoshihiro Kimura: Effect of Elastic Cantilever Column on Mechanism of Damage Control for Two Story Braced Frame with Restraint Braces, Jour. of Constr. Eng., AIJ, No. 612, pp187 pp.195, 2007.2 (in Japanese)

[5] Building Center of Japan: The Building Standard Low of Japan, 2004

[6] K. Muto, M. Nagata, H. Ueno, H. Kanayama and M. Hanajima: Earthquake response analysis system of highrise building: "FAPP-FASP" System, $1^{\text {st }}$ Symposium proceedings of the $1^{\text {st }}$ symposium on the use of computers in building engineering, pp.205-210, 1979.3

[7] Gregory A. MacRae, Yoshihiro Kimura, Charles Roeder: Effect of Column Stiffness on Braced Frame Seismic Behavior, Jour. of Structural Engineering, ASCE, Vol.130, No.3, pp.381-391, 2004.3

[8] Takashi Hasegawa, Kenji Takahashi, Mitsuo Seki, Tadaharu Nagao, Hiroki Mukai and Koji Fukuda: Comparison between seismic performance of U.S. steel perimeter and Japanese spatial moment resisting frames, Summaries of

[9] Technical Papers Annual Meeting Architectural Institute of Japan, C-1, Structures III, pp.905-908, 1998.9

[10] ABAQUS 6.4.2/Standard User's Manual 